\title{
PART 2H
}

\section{Trichomonas vaginalis infection}

\section{Mabey, J Ackers, Y Adu-Sarkodie}

$\mathrm{T}$ he organism Trichomonas vaginalis is a sexually transmissible protozoal parasite. It is the commonest curable sexually transmitted infection (STI); The World Health Organization estimates that about 170 million new cases occur annually. ${ }^{1}$ It is a common cause of vaginal discharge in women, in whom it may also cause vulval irritation and inflammation, dysuria, and inflammation of the exo-cervix. It has been associated with dysuria and urethral discharge in men but asymptomatic infection also occurs in both sexes. $T$ vaginalis infection is associated with low socioeconomic status, and is more prevalent in developing than in developed countries. ${ }^{2}{ }^{3}$ Opinions vary concerning whether or not $T$ vaginalis can be transmitted by non-sexual contact. ${ }^{45} \mathrm{~A}$ morphologically similar organism, Pentatrichomonas hominis, is a commensal of the human large intestine, but conventional wisdom has it that this organism does not multiply in the human reproductive tract.

\section{RECOMMENDED TESTS}

Microscopy of a wet mount preparation is the most commonly used diagnostic test for $T$ vaginalis infection. Characteristic motile flagellated protozoa are readily seen. Microscopy for $T$ vaginalis should be performed as soon as possible after the sample is taken as motility diminishes with time. Wet mount microscopy is approximately $70 \%$ sensitive compared to culture in women, and significantly less sensitive in men. ${ }^{6-8}$ At present, culture techniques are still regarded as the most sensitive and specific; they provide the "gold standard" against which other methods are judged (evidence level: III, recommendation grade B).

Culture media vary in efficiency but Diamond's TYM medium $^{9}$ (sometimes with minor modifications) is among the best. ${ }^{10}{ }^{11}$ Most tubes will be positive within 48 hours but should be kept for 7-10 days before being finally discarded. A very convenient, but expensive, way of culturing specimens is the InPouch system, which appears to be at least as sensitive as conventional tubed media ${ }^{12}{ }^{13}$ (evidence level III, recommendation grade $\mathrm{B}$ ).

A latex agglutination test that detects $T$ vaginalis antigen was described some years ago. This rapid and simple bedside test, which does not require electricity or special equipment, has been reported to have sensitivities of $95 \%$ and $98.8 \%$ and specificities of $99 \%$ and $92.1 \%$ compared to culture for the diagnosis of $T$ vaginalis infection in women. ${ }^{14}{ }^{15}$ This diagnostic test is available in kit form (TVlatex; Kalon Biological Ltd, Ash Vale, GU12 5QJ, UK) (evidence level III, recommendation grade $\mathrm{B}$ ).

More recently, several protocols have been described for the detection of $T$ vaginalis DNA in clinical samples using the polymerase chain reaction (PCR). ${ }^{16-19}$ Some of these assays appear to be more sensitive than culture although, as with PCR assays for Chlamydia trachomatis infection when they were first introduced, it is not immediately apparent whether samples positive by PCR and negative by culture represent false negatives by culture, or false positives by PCR. No PCR assay for $T$ vaginalis is currently on the market in the United Kingdom (evidence level III, recommendation grade B).

\section{WHO SHOULD BE TESTED?}

- Until recently $T$ vaginalis has not been considered an important pathogen since, unlike other STIs, it was not believed to cause serious sequelae. Its importance is now being reassessed in the light of recent evidence that it is associated with adverse pregnancy outcome and facilitates the sexual transmission of HIV infection. ${ }^{20-22}$ However further research is needed to confirm these associations and to prove that the association is causal. Moreover recent trials have found that treatment of $T$ vaginalis infection in pregnancy does not improve pregnancy outcome, and may be harmful. ${ }^{23-25}$ Screening of asymptomatic individuals for $T$ vaginalis infection is therefore not currently recommended (evidence level I, II, recommendation grade $\mathrm{A}$ ).

- Women attending clinics with a complaint of vaginal discharge should be tested for $T$ vaginalis infection (evidence level III, recommendation grade $\mathrm{B}$ ). It is generally recommended that sexual partners of infected women should be treated epidemiologically ${ }^{26-29}$ (evidence level $\mathrm{lb}$, recommendation grade $\mathrm{A}$ ). Testing of male partners could in theory lead to further contact tracing in those who test positive (evidence level IV, recommendation grade $\mathrm{C}$ ).

- Men with urethral symptoms which persist after infection with Neisseria gonorrhoeae, Chlamydia trachomatis, and Mycoplasma genitalium have been excluded or treated should be tested for $T$ vaginalis infection ${ }^{30}{ }^{31}$ (evidence level III, recommendation grade B).

- Test of cure is only recommended in those whose symptoms persist after treatment (evidence level IV, recommendation grade $\mathrm{C}$ ).

\section{RECOMMENDED SITES FOR TESTING}

In women, a swab should be taken from the posterior fornix at the time of speculum examination (evidence level III, recommendation grade B). Self administered vaginal swabs have been used in many recent studies, and are likely to give equivalent results ${ }^{32}$ (evidence level III, recommendation grade $\mathrm{B}$ ). First catch urine (FCU) specimens, with or without centrifugation, have also been tested in women, but the sensitivity is less than that achieved with vaginal swabs (evidence level III, recommendation grade B).

In men, urethral swabs or FCU samples are recommended. The sensitivity of FCU can be improved by testing a cell pellet after centrifugation. Sensitivity can be improved by testing both a swab and a FCU ${ }^{33} 34$ (evidence level III, recommendation grade B). Swabs from the subpreputial space may also be tested, but this method of specimen collection has not been well validated (evidence level IV, recommendation grade $\mathrm{C}$ ).

Abbreviations: $F C U$, first catch urine; $P C R$, polymerase chain reaction; STI, sexually transmitted infections 


\section{FACTORS THAT ALTER TESTS RECOMMENDED OR SITES TESTED}

None.

\section{APPLICABILITY/RESOURCE REQUIREMENTS}

The "wet prep"microscopy has little associated cost. Kalon latex agglutination costs approximately $£ 1(€ 1.48)$ and the InPouch culture approximately $£ 2$.

\section{AUDIT STANDARD}

Women attending clinics with a complaint of vaginal discharge should be tested for $T$ vaginalis infection using a recommended test-target $95 \%$.

\section{SEARCH STRATEGY}

A PubMed search of the English language literature was conducted up to December 2004, using the keywords "Trichomonas vaginalis" and "trichomoniasis". Personal libraries and the abstracts of recent meetings of the International Society for STD Research were also scrutinised.

\section{Authors' affiliations}

D Mabey, J Ackers, Y Adu-Sarkodie, Department of Infectious ad Tropical Diseases, London School of Hygiene and Tropical Medicine, London, UK

Conflict of interest: none declared.

Correspondence to: Professor David Mabey, London School of Hygiene and Tropical Medicine, London WC1E 7HT, UK; david.mabey@lshtm. ac.uk

Accepted 31 August 2006

\section{REFERENCES}

1 Gerbase AC, Rowley JT, Heyman DL, et al. Global prevalence and incidence estimates of selected curable STDs. Sex Transm Infect 1998;74(Suppl 1):s12-s16.

2 Cotch MF, Pastorek JG, Nugent PR, et al. Demographic and behavioural predictors of Trichomonas vaginalis infection among pregnant women. Obstet Gynecol 1991;78:1087-92.

3 Buvé $A$, Weis $H A$, Laga $M$, et al. The epidemiology of trichomoniasis in women in four African cities. AIDS 2001;15(Suppl 4):s89-s96.

4 Catterall RD, Nicol CS. Is trichomonal infestation a venereal disease? BMJ 1960;1:1177-9.

5 Adu-Sarkodie Y. Trichomonas vaginalis transmission in a family. Genitourin Med 1995; 71:199-200.

6 Gelbart S, Thomason J, Osypowski P, et al. Comparison of Diamond's modified medium and Kupferberg for the detection of Trichomonas vaginalis. J Clin Microbiol 1989:27:1095-6.

7 Levi MH, Torres J, Pina C, et al. Comparison of the InPouch TV culture system and Diamond's modified medium for detection of Trichomonas vaginalis. J Clin Microbiol 1997:35:3308-10.

8 Krieger JN, Tam MR, Stevens CE, et al. Diagnosis of trichomoniasis: comparison of conventional wet mount examination with cytological studies, cultures and monoclonal antibody staining of direct specimens. JAMA 1988;259:1223-7.
9 Diamond LS. The establishment of various trichomonads of animals and man in axenic cultures. J Parasitol 1957:488-90.

10 Schmid GP, Matheny LC, Zaidi AA, et al. Evaluation of six media for the growth of Trichomonas vaginalis from vaginal secretions. J Clin Microbiol 1989:27:1230-3.

11 Gelbart SM, Thomason JL, Osypowski, et al. Growth of Trichomonas vaginalis in commercial culture media. J Clin Microbiol 1990;28:962-4.

12 Borchardt KA, Smith RF. An evaluation of an InPouch TV culture method for diagnosing Trichomonas vaginalis infection. Genitourin Med $1991 ; 67: 149-52$.

13 Borchardt KA, Zhang MZ, et al. A comparison of the sensitivity of the InPouch TV, Diamond's, and Trichosel media for detection of Trichomonas vaginalis. Genitourin Med 1997;73:297-8.

14 Carney JA, Unadakt P, Yule A, et al. New rapid latex agglutination test for diagnosing Trichomonas vaginalis infection. $J$ Clin Pathol 1988:41:806-8.

15 Adu-Sarkodie Y, Opoku BK, Danso KA, et al. Comparison of latex agglutination, wet preparation, and culture for the detection of Trichomonas vaginalis. Sex Transm Infect 2004;80:201-3.

16 Mayta H, Gilman RH, Calderon MM, et al. 18S ribosomal DNA-based PCR for diagnosis of Trichomonas vaginalis. J Clin Microbiol 2000:38:2683-7.

17 Madico G, Quinn TC, Rompalo A, et al. Diagnosis of Trichomonas vaginalis infection by PCR using vaginal swabs. J Clin Microbiol 1998:36:3205-10.

18 Shaio M-F, Lin P-R, Liu J-Y. Colorimetric one tube nested PCR for detection of Trichomonas vaginalis in vaginal discharges. J Clin Microbiol 1997; 35:132-8.

19 Crucitti T, Van Dyck E, Tehe A, et al. Comparison of culture and different PCR assays for detection of Trichomonas vaginalis in self collected swab specimens. Sex Transm Infect 2003;79:393-8.

20 Cotch MF, Pastorek J, Nugent RP, et al. Trichomonas vaginalis associated with low birth weight and preterm labour. Sex Transm Dis 1997;24:353-60.

21 Laga M, Manoka A, Kivuvu M, et al. Non ulcerative sexually transmitted diseases as risk factors for HIV-1 transmission in women: results from a cohort study. AIDS 1993;7:95-102.

22 Hobbs MM, Kazembe P, Reed AW, et al. Trichomonas vaginalis as a cause of urethritis in Malawian men. Sex Transm Dis 1999:26:381-7.

23 Klebanoff MA, Carey JC, Hauth JC, et al. Failure of metronidazole to prevent preterm delivery among pregnant women with asymptomatic Trichomonas vaginalis infection. N Engl J Med 2001;345:487-93.

24 Andrews WW, Sibai BM, Thom EA, et al. Randomised controlled trial of metronidazole plus erythromycin to prevent spontaneous preterm delivery in fetal firbronectin-positive women. Obstet Gynecol 2003;101:847-55.

25 Kigozi GG, Brahmbhatt H, Wabwire-Mangen F, et al. Treatment of Trichomonas in pregnancy and adverse outcomes of pregnancy: A sub analysis of a randomized trial in Rakai, Uganda. Am J Obstet Gynecol 2003; 189:1398-400

26 Lyng J, Christensen J. A double blind study of treatment with a single dose tinidazole of partners to females with trichomoniasis. Acta Obstet Gynecol Scand 1981;60:199-201.

27 Dykers JR. Single dose metronidazole treatment for trichomonal vaginitispatient and consort. N Engl J Med 1975;293:23-4.

28 British Association for Sexual Health. 2002 National guidelines on the management of Trichomonas vaginalis (www.bashh.org).

29 Centers for Disease Control and Prevention. Sexually transmitted diseases treatment guidelines 2002. MMWR 2002;51:44-5.

30 Krieger JN, Verdon $M$, Siegel N, et al. Natural history of urogenital trichomoniasis in men. J Urol 1993;149:1455-8.

31 Holmes KK, Handsfield HH, Wang SS, et al. Etiology of non gonococcal urethritis. N Engl J Med 1975;292:1199-205.

32 Tabrizi SN, Paterson B, Fairley CK, et al. A self administered technique for the detection of sexually transmitted diseases in remote communities. $J$ Infect Dis 1997; 176:289-92.

33 Krieger JN, Verdon $M$, Siegel N, et al. Risk assessment and laboratory diagnosis of trichomoniasis in men. J Infect Dis 1992;166:1362-6.

34 Saxena SB, Jenkins RR. Prevalence of Trichomonas vaginalis in men at high risk for sexually transmitted diseases. Sex Transm Dis 1991;18:138-42. 